clinical and/or experimental studies related to this work and sponsored by AbbVie, BMS, Janssen, Pfizer and Roche; has received personal or institutional support from AbbVie, BMS, Janssen, Pfizer and Roche; has delivered speeches at events related to this work and sponsored by AbbVie, Janssen, Pfizer and Roche, Paid instructor for: Has participated in clinical and/or experimental studies related to this work and sponsored by AbbVie, BMS, Janssen, Pfizer and Roche; has received personal or institutional support from AbbVie, BMS, Janssen, Pfizer and Roche; has delivered speeches at events related to this work and sponsored by AbbVie, Janssen, Pfizer and Roche, Speakers bureau: Has delivered speeches at events sponsored by AbbVie, Janssen, Pfizer and Roche, Licia Mota Speakers bureau: Has delivered speeches at events sponsored by AbbVie, Janssen, Pfizer, Roche and UCB., Geraldo CastelarPinheiro Consultant for: Has received consulting fees from AbbVie, Bristol-Myers Squibb, Eli Lilly, Glaxosmithkline, Janssen, Pfizer, Sanofi Genzyme and Roche

DOI: 10.1136/annrheumdis-2019-eular.1582

\section{THU0136 TNF INHIBITORS IN PREGNANCY: STOP, REDUCE OR CONTINUE? - OBSERVATIONS FROM A PREGNANCY OUTPATIENT CLINIC}

Isabell Haase ${ }^{1}$, Susanna Spaethling-Mestekemper ${ }^{2}$, Matthias Schneider ${ }^{1}$, Rebecca Fischer-Betz ${ }^{1}{ }^{1}$ Heinrich-Heine-University Düsseldorf, Policlinic of Rheumatology and Hiller Research Unit, Düsseldorf, Germany; ${ }^{2}$ Rheumapraxis, Munich, Germany

Background: Women with active Rheumatoid Arthritis (RA) are more prone to relapses and complications during pregnancy. The potential risks of disease activation and treatment during gestation should be weighed in a shared decision prior to conception. An increasing number of women who wish to conceive are being treated with TNF inhibitors (TNFi). Some wish to discontinue or at least reduce therapy while pregnant and require information on opportunities and risks.

Objectives: To study the outcome of pregnancies in women with RA who either discontinued, reduced or maintained their TNFi treatment after conception.

Methods: Pregnancies from an outpatient pregnancy clinic were evaluated before conception, during each trimester and postpartum. Clinical characteristics, disease activity (DAS28-CRP), medication use and pregnancy outcome were analysed. A flare was defined as increase in clinical activity leading to intensified treatment (new treatment with prednisolone or increase in dosage $\geq 5 \mathrm{mg} /$ day and/or treatment with intraarticular glucocorticoids and/or (re-)treatment with DMARDs/TNFi). All women received extensive counselling before pregnancy based on current knowledge and subsequently decided to continue or stop TNFi at conception. If they stayed on TNFi and were in remission, women received the suggestion to stretch the therapy intervals in a disease activity guided manner.

Results: After exclusion of one miscarriage, 56 completed pregnancies were enrolled and grouped according to their decision to stop (group 1) or continue (group 2) TNFi therapy during pregnancy. The latter were subdivided into those who could stretch the therapy intervals (group 2a) and those who could not (group 2b). Group 1 also contained seven women who received Tocilizumab or Rituximab until conception.

Despite low disease activity (DAS $\leq 3.2$ ) at conception in all groups, a higher flare rate during pregnancy and postpartum was observed after discontinuation of TNFi. In addition, a higher dose of oral prednisolone and more frequent intraarticular therapy was reported in group 1 (table 1). Postpartum, 38.9\% restarted TNFi therapy. About half of the women who chose to stay on therapy during gestation were able to stretch the injection interval of their TNFi, which was either Adalimumab (every 3.0 weeks), Certolizumab (median every 4.0 [min 4.0, max 5.0] weeks) or Etanercept (median every 3.0 [min 2.0, max 6.0] weeks) (Table 2). Relapse rate as well as prednisolone consumption was comparable between group $2 \mathrm{a}$ and group $2 \mathrm{~b}$.
Abstract THU0136 -Table 1.

\begin{tabular}{|c|c|c|c|}
\hline & \multirow{2}{*}{$\begin{array}{l}\text { TNFi exposure until } \\
\text { conception }(\mathrm{N}=37)\end{array}$} & \multicolumn{2}{|c|}{$\begin{array}{l}\text { Pregnancies with ongoing } \\
\text { TNFi exposure }(\mathrm{N}=19)\end{array}$} \\
\hline & & $\begin{array}{c}\text { Successful } \\
\text { reduction }(\mathrm{N}=9)\end{array}$ & $\begin{array}{c}\text { No reduction } \\
\text { possible }(\mathrm{N}=10)\end{array}$ \\
\hline \multicolumn{4}{|c|}{ Patient characteristics at conception } \\
\hline Age (years), median (IQR) & $32(29-36)$ & $32(30-34)$ & $36(34.25-36.75)$ \\
\hline Disease duration (months), median (IQR) & $80(48-204)$ & 96 (84-276) & $70(54-109.5)$ \\
\hline Seropositivity, n (\%) & $21(56.8 \%)$ & $5(55.6 \%)$ & $8(80.0 \%)$ \\
\hline DAS28, median (IQR) & $2.8(2.5-3.1)$ & $2.9(2.5-3.0)$ & $2.7(2.6-2.9)$ \\
\hline Prednisolone (mglday), (median, IQR) & $5.0(5.0-7.0)$ & $5.0(3.5-5.0)$ & $5.0(3.5-5.0)$ \\
\hline Sulfasalazine, $n(\%)$ & $2(5.4 \%)$ & $3(33.3 \%)$ & - \\
\hline$H C Q, n(\%)$ & $1(2.7 \%)$ & $2(22.2 \%)$ & $3(30.0 \%)$ \\
\hline \multicolumn{4}{|c|}{ Pregnancy outcomes } \\
\hline \multicolumn{4}{|l|}{ DAS28-CRP $\leq 3.2, n(\%)$} \\
\hline $1^{\text {st }}$ trimester & $23(62.2 \%)$ & $8(88.9 \%)$ & $8(80.0 \%)$ \\
\hline $2^{\text {no }}$ trimester & $16(43.2 \%)$ & $8(88.9 \%)$ & $8(80.0 \%)$ \\
\hline $3^{r \text { rd trimester }}$ & $23(62.2 \%)$ & $8(88.9 \%)$ & $8(80.0 \%)$ \\
\hline 3 months postpartum & $18(48.6 \%)$ & $7(77.8 \%)$ & $7(70.0 \%)$ \\
\hline 6 months postpartum & $28(76.5 \%)$ & $7(77.8 \%)$ & $8(80.0 \%)$ \\
\hline Flare during pregnancy, $n(\%)$ & $25(67.6 \%)$ & - & $2(20.0 \%)$ \\
\hline Flare postpartum, $n(\%)$ & $19(51.4 \%)$ & $2(22.2 \%)$ & $2(20.0 \%)$ \\
\hline Preterm birth', n $(\%)$ & $10(27.0 \%)$ & $1(11.1 \%)$ & - \\
\hline Low birth weight ${ }^{2}$, n $(\%)$ & $7(19.0 \%)$ & - & - \\
\hline Breastfeeding, $n(\%)$ & $25(67.6 \%)$ & $9(100.0 \%)$ & $9(90.0 \%)$ \\
\hline \multicolumn{4}{|c|}{ Glucocorticoid use during pregnancy } \\
\hline \multicolumn{4}{|l|}{ Prednisolone (mg/day), (median, IQR) } \\
\hline $1^{s t}$ trimester & $10.0(5.0-10.0)$ & $5.0(5.0-5.75)$ & $5.0(3.5-5.0)$ \\
\hline $2^{n \text { tr trimester }}$ & $10.0(10.0-15.0)$ & $5.0(5.0-5.75)$ & $5.0(3.5-7.0)$ \\
\hline $3^{\text {(nd t trimester }}$ & $10.0(9.5-13.0)$ & $5.0(5.0-5.0)$ & $5.0(3.5-7.0)$ \\
\hline \multicolumn{4}{|c|}{ Of those taking prednisolone - taking $\geq 10 \mathrm{mg} / \mathrm{d}, \mathrm{n}(\%)$} \\
\hline $1^{s t}$ trimester & $15(65.2 \%)$ & $1(16.7 \%)$ & $2(20.0 \%)$ \\
\hline $2^{\text {no }}$ trimester & $23(85.2 \%)$ & - & $2(20.0 \%)$ \\
\hline $3^{(r \text { trimester }}$ & $18(75 \%)$ & - & $1(10.0 \%)$ \\
\hline Intraarticular prednisolone therapy, $\mathrm{n}(\%)$ & $17(45.9 \%)$ & - & $1(10.0 \%)$ \\
\hline
\end{tabular}

Abstract THU0136 -Table 2

\begin{tabular}{|c|c|c|c|c|}
\hline & $\begin{array}{l}\text { No } \\
\text { TNFi }\end{array}$ & Adalimumab & Certolizumab & Etanercept \\
\hline \multicolumn{5}{|c|}{ Women on therapy at preconception } \\
\hline All Groups, n (\%) & $\begin{array}{c}7 \\
(12.5 \%)\end{array}$ & $7(12.5 \%)$ & $18(32.1 \%)$ & $23(41.1 \%)$ \\
\hline Group 1, n (\%) & $\begin{array}{c}7 \\
(18.9 \%)\end{array}$ & $4(10.8 \%)$ & $8(21.6 \%)$ & $18(48.6 \%)$ \\
\hline Group 2a, n (\%) & - & $1(11.1 \%)$ & $5(55.6 \%)$ & $3(33.3 \%)$ \\
\hline Group 2b, n (\%) & - & $2(20.0 \%)$ & $6(60.0 \%)$ & $2(20.0 \%)$ \\
\hline \multicolumn{5}{|c|}{ Women of group 2a during pregnancy } \\
\hline $\begin{array}{l}\text { Therapy interval (weeks), median } \\
\text { (min-max) }\end{array}$ & - & 3.0 & $4.0(4.0-5.0)$ & $3.0(2.0-6.0)$ \\
\hline
\end{tabular}

Conclusion: Women with RA who discontinue TNFi at conception face a higher risk of flares during pregnancy and often have an increased demand for steroids to control disease activity. When in remission under ongoing TNFi therapy during pregnancy, it seems possible and safe for women to reduce the frequency of injections in a disease activity guided manner. These real-world data will help to provide women with comprehensive advice on treatment options and risks regarding TNFi therapy at pregnancy counselling.

Disclosure of Interests: Isabell Haase: None declared, Susanna Spaeth ling-Mestekemper: None declared, Matthias Schneider Grant/research sup port from: GlaxoSmithKline and UCB Pharma for performing the LuLastudy., Speakers bureau: Chugai, Rebecca Fischer-Betz Grant/research support from: GlaxoSmithKline and UCB Pharma for performing the LuLastudy.

DOI: 10.1136/annrheumdis-2019-eular.2566

\section{THU0137 SUBCLINICAL THYROID DYSFUNCTION IS A CARDIOVASCULAR DISEASE RISK IN FEMALE RHEUMATOID ARTHRITIS}

Suad Hannawi ${ }^{1}$, Haifa Hannawi ${ }^{2}$, Issa Al Salmi ${ }^{3} .{ }^{1}$ Ministry of Health and Prevention, Rheumatology, Dubai, United Arab Emirates; ${ }^{2}$ Ministry of Health and Prevention, Dubai, United Arab Emirates; ${ }^{3}$ The Royal Hospital, Muscat, Oman

Background: Rheumatoid arthritis (RA) is a multisystem autoimmune dis ease that proved to be associated with other autoimmune diseases particularly hypothyroidism. Subclinical hypothyroidism had been reported in RA. As well, RA patients are at double the risk of cardiovascular diseases (CVD). The increased risk of CVD is not fully explained by the 
traditional and non-traditional CVD risk factors. In general population, hypothyroidism had been reported as a CVD risk factor.

Objectives: This study aimed for the first time to investigating the relationship between thyroid function parameters and the CVD risk as manifested by the carotid intima media thickness (cIMT) among RA patients. Methods: All the RA patients were recruited through a specialized rheumatology clinic at the Ministry of Health and Prevention of UAE, from April 2016 to December 2018. Fasting Free thyroxine (FT4), Free triiodothyronine (FT3), and thyroid stimulating hormone (TSH) were assessed in all the participants within the same week of the CIMT measurement. Linear regression analysis used to look for the correlation of the thyroid function test (TSH, T\$, and T3) and the cIMT.

Results: A total of 154 female RA patients satisfying ACR/EULAR criteria for diagnosis of RA were recruited. None of the patients had history of thyroid, renal, or hepatic disorders. None of the patients were pregnant. The mean age for the participants was $50 \pm 12$ years (Min16 -Max 87). The mean FT4 was $15.7 \pm 3.6$ (NR: $12-22$ pmol/L), mean FT3 was 4.54 \pm 1.0 (NR: $4-6.8 \mathrm{pmol} / \mathrm{L}$ ), and mean TSH was $2.60 \pm 3.3$ (NR:0.27-4.2 $\mathrm{mIU} / \mathrm{L})$. The mean $\mathrm{CIMT}$ was $0.57 \pm 0.11 \mathrm{~mm}$. correlating TFT with CIMT showed that while there was no correlation between each of the FT3 and FT4with the CIMT ( $P$ value 0.46 and 0.19 , respectively), there were a significant negative linear relationship between TSH value and the CIMT $(P=0.03, \beta=--0.006)$

Conclusion: Subclinical thyroid dysfunction might be an additional non-traditional CVD risk factors that can help in filling the gap of understanding the increased risk of CVD in RA. Further studies at a larger scale are needed to confirm the study findings. Also, there is a need to confirm if management of thyroid dysfunction in RA may help in overall improvement of this subset of population.

\section{REFERENCES:}

[1] Atzeni F, Doria A, Ghirardello A, Turiel M, Batticciotto A, Carrabba M, Sarzi-Puttini P. Anti-thyroid antibodies and thyroid dysfunction in rheumatoid arthritis: Prevalence and Clinical Value. Autoimmunity. 2008;41:111-5.

[2] Andonopoulos A, Siambi V, Makri M, Christofidou M, Markou C, Vagenakis A. Thyroid function and immune profile in rheumatoid arthritis. A controlled study Clin Rheumatol. 1996;15:599-603.

[3] Shiroky J, Cohen M, Ballachey M, Neville C. Thyroid dysfunction in rheumatoid arthritis: a controlled prospective survey. Ann Rheum Dis. 1993;52:454-6

Disclosure of Interests: None declared

DOI: 10.1136/annrheumdis-2019-eular.3905

\section{THU0138 RHEUMATOLOGISTS' ADHERENCE TO THE TREAT-TO- TARGET PRINCIPLE IN EARLY RA PATIENTS WITHIN THE PRAGMATIC CARERA TRIAL: ROOM FOR IMPROVEMENT?}

Veerle Stouten ${ }^{1}$, Diederik De Cock $^{1}$, Sofia Pazmino ${ }^{1}$, Kristien Van der Elst ${ }^{1,2}$, Johan Joly ${ }^{2}$, Delphine Bertrand ${ }^{1,2}$, Rene Westhovens ${ }^{1,2}$, Patrick Verschueren ${ }^{1,2}$, On hehalf of the CareRA study group. ${ }^{1} \mathrm{KU}$ Leuven, Skeletal Biology and Engineering Research Center, Department of Development and Regeneration, Leuven, Belgium; ${ }^{2}$ University Hospitals Leuven, Rheumatology, Leuven, Belgium

Background: Treating to a predefined target is a principle adopted in guidelines to treat rheumatoid arthritis (RA). It is currently the most efficient strategy to control disease activity, but its implementation in daily clinical practice remains challenging.

Objectives: To evaluate rheumatologists' adherence to a treat-to-target (T2T) approach at a threshold of low disease activity (DAS28CRP $\leq 3.2$ ) in patients with early RA during the 2-year Care in early RA (CareRA) study.

Methods: CareRA is an investigator-initiated pragmatic multicentre trial, in which patients with early RA and naïve to conventional synthetic disease modifying anti-rheumatic drugs (csDMARD) were included $(n=379)$. Participants were randomized to different remission induction schemes consisting of a csDMARD combination or methotrexate (MTX) monotherapy with and without a prednisone tapering down scheme. Following the T2T approach, specific treatment adaptations had to be performed in case of DAS28CRP $>3.2$ during the first study year, unless a predefined reason not to intensify treatment was provided. As first step, dose of MTX had to be increased from $15 \mathrm{mg}$ to $20 \mathrm{mg}$ weekly. As second step, dose of the other csDMARD was escalated in the combination arms and leflunomide was added in the MTX monotherapy arms. From week (w)52 onwards, further T2T was advised but type of treatment adaptation was left at the rheumatologists' discretion. Adherence to this T2T approach
Table 1. Lipid profile in RA patient with and without IR

\begin{tabular}{lccc}
\hline Lipid parameters & $\begin{array}{c}1 \text { group } \\
\text { IR }(+) \\
(n=15)\end{array}$ & $\begin{array}{c}2 \text { group } \\
\text { IR(-) } \\
(n=32)\end{array}$ & $p$ \\
\hline TC, mmol/l & $5,5[4,8 ; 6,5]$ & $5,2[4,3 ; 5,8]$ & 0,16 \\
HDL-C, mmol/l & $1,7[1,3 ; 1,9]$ & $1,7[1,6 ; 2,1]$ & 0,25 \\
LDL-C, mmol// & $3,4[2,5 ; 4,2]$ & $2,9[2,1 ; 3,5]$ & 0,12 \\
TG, mmo/// & $1,3[0,8 ; 2,2]$ & $0,9[0,7 ; 1,1]$ & 0,007 \\
Non-HDL, mmol/l & $4,0[2,9 ; 4,9]$ & $3,2[2,6 ; 3,8]$ & 0,09 \\
TG/HDL-C ratio & $0,8[0,5 ; 1,3]$ & $0,5[0,4 ; 0,7]$ & 0,01 \\
\hline
\end{tabular}

was defined as performing a dose escalation or changing/adding DMARD medication in case of DAS28CRP $>3.2$ and was evaluated at every study visit during 2 years. Additionally, remission (DAS28CRP<2.6) rates at w104 were compared between patients in which T2T was applied at every visit and patients not always treated to target. Only data from patients for which DAS28-CRP scores were available were taken into account to evaluate the low disease activity state.

Results: The proportion of patients with DAS28CRP $>3.2$ was $26 \%$ (93/ 365 ) at w8, but decreased to a stable average of $16 \%$ on the following visits and further diminished to $10 \%(30 / 303)$ at w104. The frequency of T2T adherence in these patients varied from 59\% (55/93) at w8 to $17 \%$ $(5 / 30)$ at w104 (Figure 1). The most frequent reason not to intensify treatment during the first study year was that rheumatologists considered the disease already well-controlled. This reason was reported in $50 \%$ of non-adherent cases at $\mathrm{w} 8$, in $15 \%$ at $\mathrm{w} 16,14 \%$ at $\mathrm{w} 28$, and $24 \%$ at w40. The second most frequently given reason for non-adherence during the first study year was that giving glucocorticoids or NSAIDs temporarily was preferred over changing DMARDs, as reported in 3\% of cases at w8, $15 \%$ at $w 16,27 \%$ at w28, and $35 \%$ at $w 40$. T2T was applied at all visits in 41 out of $110(37 \%)$ patients needing at least 1 adaptation during the 2-year trial. Of these 41 patients, $36(88 \%)$ were in remission at w104, while of the 69 patients not always treated to the T2T principle, $40(58 \%)$ were in remission at the end of the 2-year trial $(p=0.001)$.

Conclusion: This study shows the difficulty of applying T2T strictly, both with and without a fixed protocol to follow. In less than half of patients theoretically in need of a treatment adaptation, treatment was intensified at all visits during the first 2 years of treatment. In the majority of cases rheumatologists gave as reason for overruling the T2T guidance that they estimated disease activity to be sufficiently controlled. However, patients in which the T2T principle was applied strictly, showed higher remission rates after 2 years of treatment.

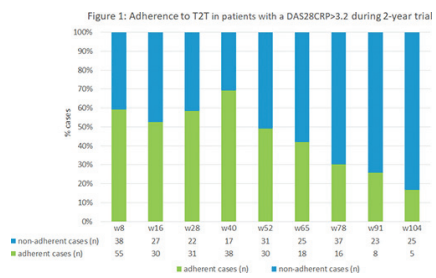

Abstract THU0138 - Figure 1

Disclosure of Interests: Veerle Stouten: None declared, Diederik De Cock: None declared, Sofia Pazmino: None declared, Kristien Van der Elst: None declared, Johan Joly: None declared, Delphine Bertrand: None declared, Rene Westhovens Grant/research support from: Bristol-Myers Squibb, Consultant for: Celltrion, Galapagos-Gilead, Patrick Verschueren Grant/research support from: Unrestricted Pfizer Grant for Early RA research

DOI: 10.1136/annrheumdis-2019-eular.7239

\section{THU0139 IS ADDING ANTI-CARP OR ANTI-PADI4 BENEFICIAL FOR DIAGNOSIS OF RHEUMATOID ARTHRITIS?}

Bogdan Kolarz ${ }^{1}$, Magdalena Dryglewska ${ }^{2}$, Marek Ciesla ${ }^{1}$, Maria Majdan ${ }^{2}$. ${ }^{1}$ University of Rzeszow, Faculty of Medicine, Rzeszow, Poland; ${ }^{2}$ Medical University of Lublin, Department of Rheumatology and Connective Tissue Diseases, Lublin, Poland

Background: Post-translatory modification (PTM), such as protein citrullination or homocitrullination (carbamylation) are key issues for the development of RA. There are known more than 300 PTMs. Some of them such as homocitrullination, are of chemical origin, but most of them (over 200) are of enzymatic origin. ACPA, anti-PADI4, anti-CarP and indirectly 